En plus de ses activités avec la Croix-Rouge, Geoffrey NewmanMorris appartint à l'Ordre de Saint-John, où il occupa une position éminente dans le prieuré australien.

De nombreuses médailles et décorations avaient été décernées à Geoffrey Newman-Morris, par la Croix-Rouge australienne aussi bien que par des Sociétés nationales étrangères, d'Asie, d'Europe ou d'Amérique, et il avait été nommé membre à vie de l'Alliance des Sociétés de la Croix-Rouge et du Croissant-Rouge d'URSS. En 1969, il avait été anobli par la reine Elizabeth et, en 1979, il avait reçu la médaille Henry Dunant, la plus haute distinction de la Croix-Rouge.

A tous ceux qui l'ont connu, Sir Geoffrey Newman-Morris laisse le souvenir d'un homme extrêmement actif, guidé par une intelligence lumineuse et par un profond sentiment d'humanité.

\title{
Décès de Charles-André Schusselé
}

La Ligue des Sociétés de la Croix-Rouge a eu le profond regret de perdre, le 17 février 1982, des suites d'un grave accident, Charles-André Schusselé, qui fut son dévoué collaborateur pendant trente-sept ans.

Il était né à Genève en 1916, d'une famille qui comptait parmi ses membres un des premiers délégués au CICR: son grand-père avait fait une mission, pendant la guerre franco-prussienne de $1870-71$, sous la direction du $\mathrm{D}^{\mathrm{r}}$ Louis Appia, l'un des fondateurs du CICR.

En se consacrant aux œuvres humanitaires après avoir obtenu sa licence en droit à l'Université de Genève, Ch.-A. Schusselé continuait donc une tradition familiale. Il présida, de 1938 à 1941, la section genevoise du "Mouvement de la Jeunesse suisse romande ". Entré au service de la Croix-Rouge suisse au début de la deuxième guerre mondiale, il fut le fondateur, en 1940-41, de son service "Secours aux enfants", qu'il dirigea jusqu'en 1943; il devint alors le chef du service central d'accueil de la Croix-Rouge suisse pour les enfants victimes de la guerre, il fonda le Centre Henry-Dunant en 1943 et s'occupa des quelque deux cent mille enfants étrangers victimes des événements qui furent reçus et hébergés en Suisse pendant ce deuxième conflit mondial.

En 1944, Ch.-A. Schusselé commença de travailler à la Ligue des Sociétés de la Croix-Rouge et demeura son collaborateur très actif jusqu'en 1981. Comme directeur du bureau "Croix-Rouge de la Jeunesse » (de 1952 à 1968), puis comme directeur des relations internationales de la Ligue, Ch.-A. Schusselé effectua d'innombrables mis- 
sions à l'étranger, visita, conseilla, encouragea les Sociétés nationales de la Croix-Rouge et s'acquit des amis dans le monde entier. Il représenta la Ligue à de nombreuses réunions internationales (à l'Unesco notamment) et fit partie à maintes reprises des délégations que la Ligue envoyait à diverses manifestations internationales.

Bien qu'il fût très occupé sur le plan mondial, Ch.-A. Schusselé restait également un membre très actif de la section locale genevoise de la Croix-Rouge suisse. En outre, il présida, à l'occasion du Centenaire de la Croix-Rouge, en 1963, le Comité d'organisation de la Conférence mondiale des éducateurs à Lausanne, et en 1978, c'est lui qui présida le Comité d'organisation des manifestations du $150^{\mathrm{e}}$ anniversaire de la naissance d'Henry-Dunant.

Les nombreux amis de Ch.-A. Schusselé lui garderont un souvenir fidèle.

\section{Adhésion aux Protocoles par la République de Maurice}

La République de Maurice a déposé, en date du 22 mars 1982, ses instruments d'adhésion aux Protocoles additionnels I et II aux Conventions de Genève du 12 août 1949 relatifs à la protection des victimes des conflits armés internationaux et non internationaux, adoptés à Genève le 8 juin 1977.

Ces instruments ont été enregistrés le 22 mars 1982 et, conformément à leurs dispositions, les Protocoles entreront en vigueur pour Maurice le 22 septembre 1982.

En comptant cette adhésion, 22 Etats sont maintenant Parties au Protocole I et 20 Etats sont Parties au Protocole II. 